Article

\title{
Methacrylate-Based Copolymers for Polymer Optical Fibers
}

\author{
Daniel Zaremba ${ }^{1}$, Robert Evert ${ }^{1}$, Laurie Neumann ${ }^{1}$, Reinhard Caspary ${ }^{1}$, Wolfgang Kowalsky ${ }^{1}$, \\ Henning Menzel ${ }^{2}$ and Hans-Hermann Johannes ${ }^{1, *}$ \\ 1 Technische Universität Braunschweig, Institut für Hochfrequenztechnik, Labor für Elektrooptik, \\ Bienroder Weg 94, 38106 Braunschweig, Germany; daniel.zaremba@ihf.tu-bs.de (D.Z.); \\ robert.evert@ihf.tu-bs.de (R.E.); laurie.neumann@tu-bs.de (L.N.); r.caspary@tu-bs.de (R.C.); \\ wolfgang.kowalsky@ihf.tu-bs.de (W.K.) \\ 2 Technische Universität Braunschweig, Institut für Technische Chemie, Abt. Makromolekulare Stoffe, \\ Hans-Sommer-Str. 10, 38106 Braunschweig, Germany; h.menzel@tu-bs.de \\ * Correspondence: h2.johannes@ihf.tu-bs.de; Tel.: +49-531-391-2006 \\ Academic Editor: Ji Ho Youk \\ Received: 28 November 2016; Accepted: 18 January 2017; Published: 25 January 2017
}

\begin{abstract}
Waveguides made of poly-methyl-methacrylate (PMMA) play a major role in the homogeneous distribution of display backlights as a matrix for solid-state dye lasers and polymer optical fibers (POFs). PMMA is favored because of its transparency in the visible spectrum, low price, and well-controlled processability. Nevertheless, technical drawbacks, such as its limited temperature stability, call for new materials. In this work, the copolymerization technique is used to modify the properties of the corresponding homopolymers. The analytical investigation of fourteen copolymers made of methyl-methacrylate (MMA) or ethyl-methacrylate (EMA) as the basis monomer is summarized. Their polymerization behaviors are examined by NMR spectroscopy with subsequent copolymerization parameter evaluation according to Fineman-Ross and Kelen-Tüdös. Therefore, some $r$-parameter sets are shown to be capable of copolymerizations with very high conversions. The first applications as high-temperature resistant (HT) materials for HT-POFs are presented. Copolymers containing isobornyl-methacrylate (IBMA) as the comonomer are well-suited for this demanding application.
\end{abstract}

Keywords: methacrylate; copolymer; POF; reactivity ratios; $Q, e$-scheme

\section{Introduction}

The growing volume of digital data in all areas of life [1] raises great demands for faster communication systems, increasing data rates, and a stronger focus on eco-friendly components. These demands will result in the replacement of today's electronic components by optical technology [2]. For in-house communication, polymer optical fibers (POFs) already demonstrate the potential to replace the current electrical wiring technology, especially because bit rates up to $1 \mathrm{Gbit} / \mathrm{s}$ over a distance of up to $50 \mathrm{~m}$ with a standard multi-mode step index POF (SI-POF) have been established [3,4]. Those step index fibers are easy to handle and, thus, end-user friendly [5]. New fiber types, such as the gradient index POF (GI-POF) or the perfluorinated GI-POF, have entered the rapidly growing market [6,7]. These new fiber types open up new fields of potential applications, e.g., professional video broadcasting services [8,9], providing even faster data communication over longer distances [10], and will probably serve as the replacement for HDMI cables [11,12]. Recent progress, e.g., the development of the Ball-Pen-Lens [13], allows for a simpler and more reliable, but less costly, connection system. This will increase the attractiveness of the POF systems compared to competing products based on silica glass fibers. 
In general, there are two well-established methods for manufacturing POFs. Continuous production is based on an extrusion process [14]. Fiber pulling from a preform allows only a limited fiber length because of the limited volume of the preform, but results in the better performance of the fibers [15]. Although both processes allow the production of POFs, the material requirements are different. Whereas the extrusion process uses polymer granules or liquid monomer, the preform process requires high-quality solid preforms. Those preforms can be prepared with limited quality by extrusion or with outstanding quality by direct bulk polymerization [16]. At first glance, this method appears to be less attractive because of the long polymerization times, as well as the complex temperature programs. However, besides the outstanding quality, the following advantages should be mentioned:

- significantly less material requirements,

- short fibers can be produced in a rapid and efficient manner,

- process variations can be implemented from run to run.

For applications in harsh environments with high temperatures, mechanical stress, and elevated humidity, POFs are still insufficient because of material deficiencies [17]. However, as exigent applications in the automotive or aerospace industry, as well as in mechanical engineering, require stringent specifications, novel or ongoing developments of existing materials become inevitable. Moreover, for specific temperature-resistant POFs, sensor POFs, or active POFs, the use of specially-designed polymers is recommended [18-20]. Therefore, the copolymerization technique provides a possibility to modify the most frequently used homopolymer PMMA, for example, in a reaction with commercially available methacrylates as comonomers, whereby the positive properties of PMMA substantially increase. Examples for tunable properties are the refractive index [21], the glass transition temperature $(\mathrm{Tg})$ [22-24], and the optical gain by the introduction of polymerizable dyes [25]. However, the use of copolymers always bears the risk of an optical performance loss in the fiber caused by scattering losses and optical heterogeneities in the polymer distribution [26]. As an alternative to copolymers polycarbonates (PC) can be used for HT-POFs as well. However, this results in problems with the preparation, purification and in particular the achievement of high molecular weights which is a key factor for fiber drawing [27]. In general, it is important to monitor the polymerization process and to observe the reaction behavior. For copolymers, the $r$-parameters or copolymerization parameters are of particular interest [28]. These parameters can be experimentally determined by (1) proton nuclear magnetic resonance $\left({ }^{1} \mathrm{H}-\mathrm{NMR}\right)$ spectroscopy for copolymers with low conversions using the linearization methods according to Fineman-Ross (FR) [29] and Kelen-Tüdös (KT) [30]; or (2) empirically using the Alfrey-Price (AP) Q,e-scheme [31]. Deviations in the polymer composition can be estimated by these techniques. The full understanding of the used polymers and their reaction behavior is of fundamental importance for the polymer, the preform process, and the resulting POF.

\section{Materials and Methods}

\subsection{General Information}

${ }^{1} \mathrm{H}-\mathrm{NMR}$ spectra were recorded on a VARIAN Oxford 200 spectrometer (Oxford Instruments, Abingdon, UK) in $\mathrm{CDCl}_{3} 99.8 \%$ (Deutero $\mathrm{GmbH}$, Kastellaun, Germany) with a 45.0 degree pulse, a relaxation time of $5 \mathrm{~s}$, and 32 repetitions at room temperature. Tetramethylsilane (TMS) was used as an internal reference for the chemical shift. Thermal analysis was performed on a Mettler Toledo DSC 1 (Mettler-Toledo, Columbus, OH, USA), Star ${ }^{\mathrm{e}}$ System for Tg measurement by differential scanning calorimetry (DSC) in three cycles with a heating rate of $10 \mathrm{~K} \cdot \mathrm{min}^{-1}$ and a cooling rate of $10 \mathrm{~K} \cdot \mathrm{min}^{-1}$. Thermo gravimetric analysis (TGA) was performed on a Netsch TG 209 cell (Netzsch, Selb, Germany). On this instrument, decomposition measurements were conducted up to $600{ }^{\circ} \mathrm{C}$. For optical measurements, an Ocean Optics QE 65000 spectrometer (Ocean Optics, Dunedin, FL, USA), a Perkin Elmer Lambda 9 UV/VIS/NIR-spectrometer (PerkinElmer, Waltham, MA, USA), and a Perkin Elmer Frontier FT-IR spectrometer were available. Spectroscopic ellipsometry was performed on a 
Sentech SENpro spectral ellipsometer (SENTECH Instruments GmbH, Berlin, Germany). Optical fibers were drawn on a recently developed POF-drawing tower [32]. RMAT708 (Raymat Materials, $n=1.404,589 \mathrm{~nm}$ ) cured with a Lighthammer-UV lamp was used as cladding material. All solvents, monomers, and the initiator were obtained from Sigma Aldrich (St. Louis, MO, USA). The chain transfer reagent 1-butyl-mercaptan was purchased from Acros Organics (Morris Plains, NJ, USA). Solvents of High-performance liquid chromatography (HPLC) quality, lauroylperoxide (97\%) and butyl mercaptan (99\%), were used without further purification. Technical grade solvents were distilled before use. MMA was dried over water-free $\mathrm{CaCl}_{2}$, distilled, and then filtered over aluminium oxide (ALOX, Aluminia N—super I, MP Biomedicals). All other monomers were filtered over ALOX prior use.

\subsection{Copolymer Preparation}

\subsubsection{Precipitated Copolymers}

In total, $3 \mathrm{~mL}$ of ice-cooled $\left(-10{ }^{\circ} \mathrm{C}\right)$ liquid base monomer methyl-methacrylate (MMA) or ethyl-methacrylate (EMA) and liquid comonomer (MMA, EMA, propyl-methacrylate (PrMA), $n$-butyl-methacrylate ( $n$-ButMA), $t$-butyl-methacrylate ( $t$-ButMA), cyclohexane-methacrylate (CHMA), benzyl-methacrylate (BzMA) or iso-bornyl-methacrylate (IBMA)) were mixed in various compositions in sealed glass vials $(\varnothing 20 \mathrm{~mm})$. Next, lauroylperoxide $(0.03 \mathrm{~mol} \%)$ was added. The solutions were degassed with nitrogen for $30 \mathrm{~min}$ and then allowed to warm up to room temperature. Subsequently, the reaction mixtures were heated to $60^{\circ} \mathrm{C}$ under constant shaking for 60 to $240 \mathrm{~min}$. At $10 \%$ cumulated monomer conversion by weight, the polymerizations were stopped by rapid cooling. Next, the polymers were diluted with dichloromethane, precipitated in methanol, washed with pentane, and dried under vacuum. ${ }^{1} \mathrm{H}-\mathrm{NMR}\left(200 \mathrm{MHz}, \mathrm{CDCl}_{3}-d_{1}, \delta\right)$ : poly(MMA-co-EMA) 3.59 (singlet (s), 3H; $\mathrm{CH}_{3}$, reference peak (ref. p.) to identify MMA), 4.03 (quartet (q), $2 \mathrm{H}, J=7 \mathrm{~Hz} ; \mathrm{CH}_{2}$, ref. p. EMA); poly(MMA-co-PrMA) 3.53 (s, 3H; $\mathrm{CH}_{3}$, ref. p. MMA), 3.85 (multiplet (m), 2H; $\mathrm{CH}_{2}$, ref. p. PrMA); poly(MMA-co-n-ButMA) 3.60 (s, 3H; $\mathrm{CH}_{3}$, ref. p. MMA), $3.95\left(\mathrm{~m}, 2 \mathrm{H} ; \mathrm{CH}_{2}\right.$, ref. p. n-ButMA); poly(MMA-co-t-ButMA) 3.53 (s, 3H; $\mathrm{CH}_{3}$, ref. p. MMA), 1.35 (s, 9H; $\mathrm{CH}_{3}$, ref. p. $t$-ButMA); poly(MMAco-CHMA) 3.60 (s, 3H; $\mathrm{CH}_{3}$, ref. p. MMA), 4.67 (m, 1H; $\mathrm{CH}$, ref. p. CHMA); poly(MMA-co-BzMA) 3.57 (s, 3H; $\mathrm{CH}_{3}$, ref. p. MMA), 7.34 (s, 5H; Ar-H, ref. p. BzMA); poly(MMA-co-IBMA) 3.60 (s, 3H; $\mathrm{CH}_{3}$, ref. p. MMA), 4.37 (m, 1H; CH, ref. p. IBMA); poly(EMA-co-MMA) 4.03 (q, $2 \mathrm{H}, J=7 \mathrm{~Hz} ; \mathrm{CH}_{2}$, ref. p. EMA), 3.59 (s, 3H; $\mathrm{CH}_{3}$, ref. p. MMA); poly(EMA-co-PrMA) 1.23 (s, 3H; $\mathrm{CH}_{3}$, ref. p. EMA), 3.87 (s, 2H; $\mathrm{CH}_{2}$, ref. p. PrMA); poly(EMA-co-n-ButMA) 1.24 (m, 3H; $\mathrm{CH}_{3}$, ref. p. EMA), $1.93-0.86$ (m, 7H, ref. p. n-ButMA); poly(EMA-co-t-ButMA) 4.02 (m, 2H; $\mathrm{CH}_{2}$, ref. p. EMA), 1.39 (s, 9H; $\mathrm{CH}_{3}$, ref. p. t-ButMA); poly(EMA-co-CHMA) 4.02 (m, 2H; $\mathrm{CH}_{2}$, ref. p. EMA), 4.64 (m, 1H; $\mathrm{CH}$, ref. p. CHMA); poly(EMA-co-BzMA) 3.95 (m, 2H; $\mathrm{CH}_{2}$, ref. p. EMA), 4.91 (s, 2H; $\mathrm{CH}_{2}$, ref. p. BzMA); poly(EMA-co-IBMA) 4.06 (m, 2H; $\mathrm{CH}_{2}$, ref. p. EMA), 4.37 (m, 1H; $\mathrm{CH}$, ref. p. IBMA).

\subsubsection{Solid Copolymer Samples}

In total, $2 \mathrm{~mL}$ of ice-cooled $\left(-10^{\circ} \mathrm{C}\right)$ liquid base monomer and liquid comonomer were mixed in sealed glass vials $(\varnothing 20 \mathrm{~mm})$ in various compositions. Next, lauroylperoxide $(0.03 \mathrm{~mol} \%)$ and butyl-mercaptan $(0.2 \mathrm{~mol} \%)$ were added. The solutions were degassed with nitrogen for $30 \mathrm{~min}$ and allowed to warm to room temperature. The vials were heated for 3 days at $50{ }^{\circ} \mathrm{C}$ and for another 2 days at $100{ }^{\circ} \mathrm{C}$. After slow cooling to room temperature, the glass was broken and the polymer samples were then cleaned by blowing-off with nitrogen.

\subsubsection{Polymer Fiber Production}

A nitrogen saturated solution of the monomer or a mixture of comonomers with lauroylperoxide $(0.03 \mathrm{~mol} \%)$ and 1-butyl-mercaptan $(0.2 \mathrm{~mol} \%)$ was filled in borosilicate tubes with a diameter of $10 \mathrm{~mm}$. These were sealed with silicon plugs and then transferred into a programmable heating cabinet. The preforms were heated slowly $\left(0.5^{\circ} \mathrm{C} / \mathrm{h}\right)$ to $60^{\circ} \mathrm{C}$. Next, this temperature was maintained constant 
for 3 days before it was raised to $100{ }^{\circ} \mathrm{C}$ for another 2 days. Finally, the temperature program ended with a rapid cooling step to $-20^{\circ} \mathrm{C}$. After the removal of the glass, the polymer rods (preforms) were cleaned with isopropanol. Subsequently, the preforms were annealed in a vacuum oven at $100{ }^{\circ} \mathrm{C}$ for at least 3 days. Afterwards, they were mounted in the heater unit of the drawing tower, heated to $230{ }^{\circ} \mathrm{C}$, and were then pulled by applying a constant force. For standard SI-POF, a core diameter of $980 \mu \mathrm{m}$ is targeted; the diameter is controlled by laser measuring units. In a second step, a $20 \mu \mathrm{m}$ film of RMAT708 is applied through a nozzle and then cured by irradiation with UV light to form the cladding material. The obtained fiber is rolled up and dried for $24 \mathrm{~h}$ at $40{ }^{\circ} \mathrm{C}$.

\section{Results and Discussion}

\subsection{Monomer Selection and Experimental Setup}

The monomer selection for this study is based on a number of criteria. MMA is already in use for POF; therefore, methacrylate-type monomers were used to ensure a structural similarity and a good ability to copolymerize. Starting from the methyl ester, the homologous series has been extended to higher alkyl and more nonpolar molecules. These molecules range from ethyl- and propyl- to iso and tert. butyl-methacrylate. Furthermore, two bulky, but purely aliphatic, derivatives (cyclohexyl- and isobornyl-methacrylate), and one aromatic compound (benzyl-methacrylate), were chosen. All used monomers, as well as the literature values for Alfrey-Price $Q, e$-values, are shown in Figure 1. From monomers with long, freely-rotatable alkyl chains, a plasticizing effect can be expected. However, bulky side groups will stiffen the polymer chain and lead to increased temperature resistance. Overall, this complete material set can lead to an adjustment of the glass transition temperature and the material load-carrying capacity in both directions.

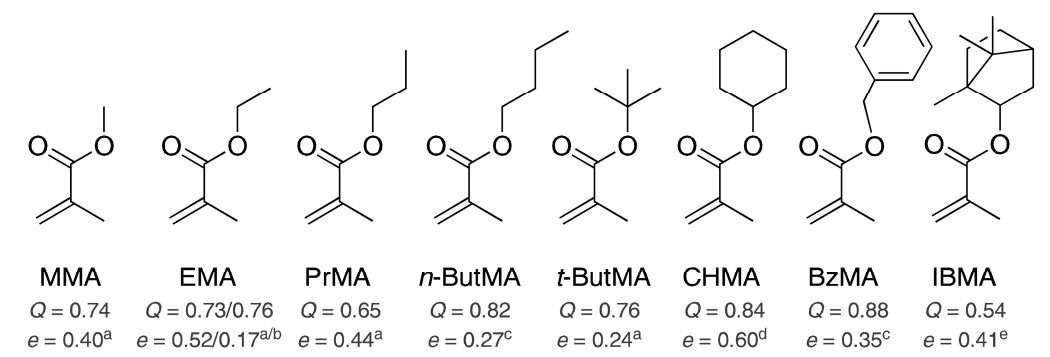

Figure 1. (Co)-monomers with the corresponding $Q, e$-values taken from ${ }^{a}$ [33], ${ }^{b}$ [34], ${ }^{c}$ [35], ${ }^{d}$ [36], and $^{\mathrm{e}}[37]$.

From the semi-empirical $Q, e-$-values, the initial reaction trends can be derived. For example, the decreasing $e$ from ethyl- ([33]) and propyl- to iso and tert. butyl-methacrylate is well-founded because of a decrease in the polarity of the molecules and thus in the double bond. The electron-rich molecule BzMA has the highest activity value of $Q$ because of a destabilizing transition state. The $Q, e$-values can be used to predict the reactivity ratios. In a first approximation, all targeted copolymers will give $r$-parameters of approximately 1 (compare Table 1 ), which makes them suitable for our application. However, a problem with this method is caused by their determination, which is performed relative to styrene in nonstandard experiments. Consequently, the interrelationship of temperature, solvents, initiators, or other additives must be considered. For example, the values for EMA given in different reports vary, as shown in Figure 1. In this case, the $Q$ values are still similar to each other, whereas the $e$ values have a difference of 0.35 . In a particular context, both $Q, e$ sets will give beneficial results. For example, in a copolymer of MMA-co-EMA, the $r$-parameters are computed as $r_{1}=1.064$ and $r_{2}=0.927$ with $Q=0.73$ and $e=0.52$ [33], or as $r_{1}=0.888$ and $r_{2}=1.006$ with $Q=0.76$ and $e=0.17$ [34]. The expected compositions of the copolymers are contrasting. In our case, it has been shown that the $Q, e$-value set with a lower activity and a higher polarization coefficient taken from Koike et al. [33] works better for the reaction of EMA as the base monomer, whereas the 
$Q, e$-values taken from Brandrup et al. [34] are more suitable for the copolymerization of MMA with EMA. In summary, a dependence on the experimental conditions, especially on the solvent, is found in our experiment.

Table 1. Calculated copolymerization parameters from literature-based $Q, e$-Values (AP) and from experimental data evaluated with calculations following Fineman-Ross (FR) and Kelen-Tüdös (KT). General $\mathrm{Tg}$ trend for an uprising commoner content.

\begin{tabular}{|c|c|c|c|c|}
\hline Copolymer & $\begin{array}{c}\text { Copolymer } \\
\text { Parameter (AP) }{ }^{a}\end{array}$ & $\begin{array}{c}\text { Copolymer } \\
\text { Parameter (FR) }\end{array}$ & $\begin{array}{c}\text { Copolymer } \\
{\text { Parameter }(K T)^{c}}^{c}\end{array}$ & $\mathrm{Tg}$ Trend \\
\hline MMA:EMA ${ }^{d}$ & $\begin{array}{l}r_{1}=0.888 \\
r_{2}=1.068\end{array}$ & $\begin{array}{l}r_{1}=0.680 \\
r_{2}=0.777\end{array}$ & $\begin{array}{l}r_{1}=0.753 \\
r_{2}=0.912\end{array}$ & - \\
\hline MMA:PrMA & $\begin{array}{l}r_{1}=1.157 \\
r_{2}=0.863\end{array}$ & $\begin{array}{l}r_{1}=0.758 \\
r_{2}=1.080\end{array}$ & $\begin{array}{l}r_{1}=0.761 \\
r_{2}=1.090\end{array}$ & - \\
\hline MMA:n-ButMA & $\begin{array}{l}r_{1}=0.857 \\
r_{2}=1.148\end{array}$ & $\begin{array}{l}r_{1}=0.694 \\
r_{2}=1.047\end{array}$ & $\begin{array}{l}r_{1}=0.733 \\
r_{2}=1.145\end{array}$ & - \\
\hline MMA:t-ButMA & $\begin{array}{l}r_{1}=0.913 \\
r_{2}=1.067\end{array}$ & $\begin{array}{l}r_{1}=0.641 \\
r_{2}=1.468\end{array}$ & $\begin{array}{l}r_{1}=0.685 \\
r_{2}=1.605\end{array}$ & + \\
\hline MMA:CHMA & $\begin{array}{l}r_{1}=0.954 \\
r_{2}=1.007\end{array}$ & $\begin{array}{l}r_{1}=0.925 \\
r_{2}=1.170\end{array}$ & $\begin{array}{l}r_{1}=0.933 \\
r_{2}=1.201\end{array}$ & o \\
\hline MMA:BzMA & $\begin{array}{l}r_{1}=0.824 \\
r_{2}=1.210\end{array}$ & $\begin{array}{l}r_{1}=0.447 \\
r_{2}=1.261\end{array}$ & $\begin{array}{l}r_{1}=0.475 \\
r_{2}=1.373\end{array}$ & - \\
\hline MMA:IBMA & $\begin{array}{l}r_{1}=1.376 \\
r_{2}=0.727\end{array}$ & $\begin{array}{l}r_{1}=0.807 \\
r_{2}=0.546\end{array}$ & $\begin{array}{l}r_{1}=0.883 \\
r_{2}=0.765\end{array}$ & + \\
\hline EMA:MMA ${ }^{d}$ & $\begin{array}{l}r_{1}=1.068 \\
r_{2}=0.888\end{array}$ & $\begin{array}{l}r_{1}=0.777 \\
r_{2}=0.680\end{array}$ & $\begin{array}{l}r_{1}=0.912 \\
r_{2}=0.753\end{array}$ & + \\
\hline EMA:PrMA & $\begin{array}{l}r_{1}=1.077 \\
r_{2}=0.922\end{array}$ & $\begin{array}{l}r_{1}=1.634 \\
r_{2}=1.088\end{array}$ & $\begin{array}{l}r_{1}=1.552 \\
r_{2}=1.005\end{array}$ & - \\
\hline EMA:n-ButMA & $\begin{array}{l}r_{1}=0.782 \\
r_{2}=1.202\end{array}$ & $\begin{array}{l}r_{1}=0.292 \\
r_{2}=0.690\end{array}$ & $\begin{array}{l}r_{1}=0.339 \\
r_{2}=0.828\end{array}$ & - \\
\hline EMA:t-ButMA & $\begin{array}{l}r_{1}=0.830 \\
r_{2}=1.113\end{array}$ & $\begin{array}{l}r_{1}=1.145 \\
r_{2}=1.544\end{array}$ & $\begin{array}{l}r_{1}=1.106 \\
r_{2}=1.481\end{array}$ & + \\
\hline EMA:CHMA & $\begin{array}{l}r_{1}=0.906 \\
r_{2}=1.097\end{array}$ & $\begin{array}{l}r_{1}=0.659 \\
r_{2}=0.973\end{array}$ & $\begin{array}{l}r_{1}=0.727 \\
r_{2}=1.159\end{array}$ & + \\
\hline EMA:BzMA & $\begin{array}{l}r_{1}=0.759 \\
r_{2}=1.279\end{array}$ & $\begin{array}{l}r_{1}=0.587 \\
r_{2}=0.976\end{array}$ & $\begin{array}{l}r_{1}=0.728 \\
r_{2}=1.366\end{array}$ & - \\
\hline EMA:IBMA & $\begin{array}{l}r_{1}=1.277 \\
r_{2}=0.774\end{array}$ & $\begin{array}{l}r_{1}=0.786 \\
r_{2}=0.269\end{array}$ & $\begin{array}{l}r_{1}=1.000 \\
r_{2}=0.811\end{array}$ & + \\
\hline
\end{tabular}

a Alfrey-Price method (calculated); ${ }^{\mathrm{b}}$ Fineman-Ross method; ${ }^{\mathrm{c}}$ Kelen-Tüdös method; ${ }^{\mathrm{d}}$ Calculated with $Q, e$ from [34].

Based on the eight selected monomers, a set of fourteen different copolymers is synthesized by choosing MMA and EMA as the base monomers. To produce preforms, the polymerizations are conducted in bulk. No additional solvents are used to minimize solvent impurities and mixing effects. As additives, only lauroylperoxide, as the thermal initiator, and 1-butyl-mercaptan, as the chain transfer reagent, were added to the nitrogen-saturated monomers solution. The combination of lauroylperoxide as the initiator and 1-butyl-mercaptan as the transfer agent is popular for POFs [21,38,39] because lauroylperoxide dissociates to non-gaseous products at mild conditions $\left(t_{1 / 2}=10 \mathrm{~h}, 61^{\circ} \mathrm{C}\right)$, thus preventing inclusions or air bubbles in the polymer. The selected ratio from lauroylperoxide to 1-butyl-mercaptan ranging from 0.03 to $0.2 \mathrm{~mol} \%$ results in the production of polymers with a degree of polymerization, $P_{n}$, of approximately 900 . This value has been found in our research group [40] to be particularly useful for fiber drawing and is also confirmed in the literature [21].

For the determination of the copolymerization parameters, two monomers $\mathrm{M}_{1}$ and $\mathrm{M}_{2}$ were copolymerized by free radical polymerization at $60{ }^{\circ} \mathrm{C}$ in different ratios with constant shaking. The polymerization process is stopped by rapid cooling in an ice bath to obtain a $10 \mathrm{wt} \%$ monomer 
conversion, which typically occurs after $3 \mathrm{~h}$. The yield is determined for the precipitated, cleaned, and vacuum-dried polymer by gravimetry compared to the amount of monomer used.

\subsection{Copolymerization Parameters}

The compositions of the copolymers are determined by ${ }^{1} \mathrm{H}-\mathrm{NMR}$ using characteristic signals corresponding to specific groups of each monomer. Selected peaks and their chemical shifts are given in the experimental section. The $r$-parameters were calculated using the methods of Fineman-Ross [29] and Kelen-Tüdös [30] and were then compared with the values calculated using the $Q, e-$-method. The molar fractions in the monomeric solution $\left(\mathrm{M}_{1}\right)$ are plotted against the molar fraction in the polymer $\left(\mathrm{m}_{1}\right)$ to give the copolymerization diagram. To calculate the monomer distribution as a function of the $r$ values, the Mayo-Lewis equation is used [41]. The determined $r$-parameters for the 14 featured copolymers in this work are listed in Table 1 . Additionally, the $r$-parameters calculated from the Alfrey-Price $Q, e$-values, and a general $\mathrm{Tg}$ trend are also shown and will be discussed in the upcoming section.

All tested monomer combinations lead to copolymers. Due to the chemical diversity of the tested monomers, a wide variation in the results is not unexpected. Assuming that a truly random copolymerization is an optimal condition for bulk polymerizations, a quality benchmark can be set. For such copolymerization, both $r$-parameters should be equal to 1 . The probability of finding the adjusted monomer composition from the feed in the resulting polymer is given for every possible monomer mixture. This is a necessary condition for the preform production because, otherwise, a non-uniform polymer distribution will result. Otherwise, the copolymers would have areas with varying compositions, which might lead to differences in the optical, thermal and chemical behavior. Polymer rods can serve as an example: having a non-uniform distribution, these polymers can already melt at a certain temperature at one end, whereas they are still solid at the other. In this case, fiber drawing, which is actually a thermoplastic transformation, is no longer possible. However, even for copolymerizations with $r$-parameters differing from $r=1$, useful bulk copolymerizations can be performed when an azeotropic point is present in the copolymerization diagram. Such an azeotropic point can be found when both $r$-parameters are lower than 1 . At the azeotropic point, the monomer mixtures in both the feed and in the resulting polymer are equal. The specific composition can be calculated and is also suitable for bulk polymerizations. However, if the $r$-parameters show large deviations from 1 in both directions, then the monomer distribution in the polymer will be non-uniform for the most compositions. Therefore, such comonomer pairs are not applicable for our implementation.

Figure 2 shows a copolymerization-parameter-plot (CPP), which includes the copolymerization parameters for all 14 copolymers (symbols). The values in the CPP are sorted by the method of their determination, which are highlighted by color (light grey: Alfrey-Price, dark grey: Finemann-Ross, and black: Kelen-Tüdös). With the CPP, the most important copolymer features can be read out. The horizontal and vertical guide lines intersect at the point $r_{1}=1, r_{2}=1$. Copolymers meeting this point react truly randomly. The closer the points are to this point, the greater is the range in which the polymer behaves almost truly randomly. Copolymers placed near the center are, therefore, the highest classified and usable for bulk polymerizations. Materials fulfilling these parameters can be used in principle. The second class of usable polymers can be observed in the third quadrant. For these copolymers, $r_{1}<1$ and $r_{2}<1$ applies. It follows that these copolymers have an azeotropic point and can be prepared in a defined composition. The remaining copolymers are of subsidiary interest for the present application. Moreover, the points of the individual copolymers can be linked. The connection forms a triangle. Depending on the size of this triangle, the compliance of each method can be detected as another benefit. 


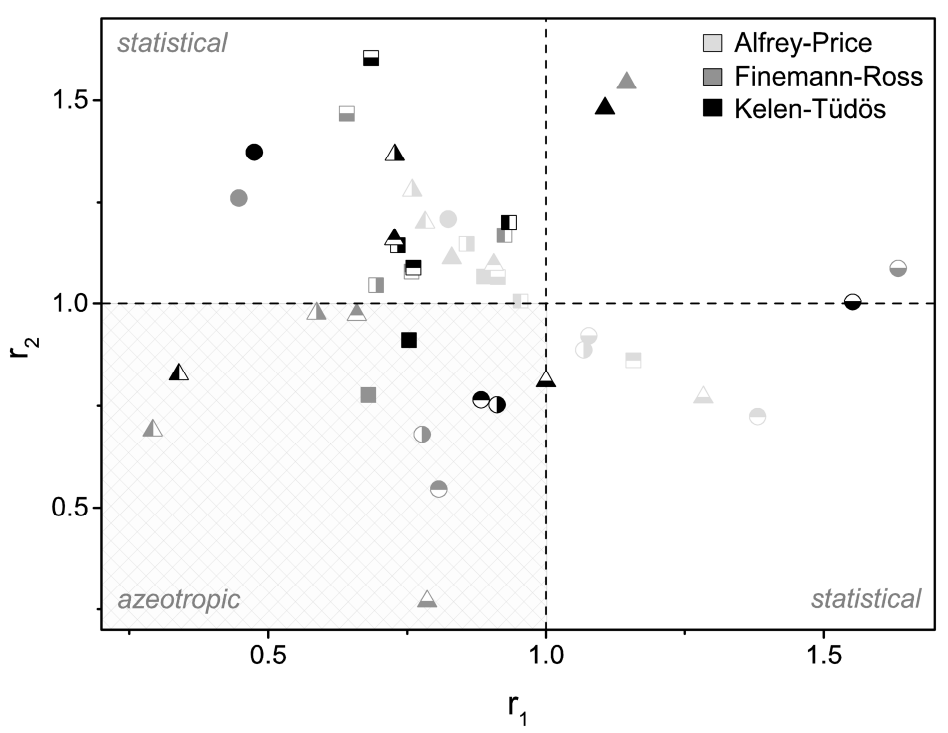

Figure 2. Copolymerization parameter ( $r$-parameter) plot for the following copolymers: MMA-co-EMA (filled squares), MMA-co-PrMA (half-filled squares top), MMA-co-n-ButMA (half-filled squares right), MMA-co-t-ButMA (half-filled squares bottom), MMA-co-CHMA (half-filled squares left), MMA-co-BzMA (filled circle), MMA-co-IBMA (half-filled circle top), EMA-co-MMA (half-filled squares right), EMA-co-PrMA (half-filled circle bottom), EMA-co- $n$-ButMA (half-filled triangle left), EMA-co-t-ButMA (filled triangle), EMA-co-CHMA (half-filled triangle top), EMA-co-BzMA (half-filled triangle right), and EMA-co-IBMA (half-filled triangle bottom). Different colors indicate the method according to which the parameters were determined as follows: light grey, Alfrey-Price; dark grey, Finemann-Ross; and black, Kelen-Tüdös. The individual squares highlight the copolymer types.

On the basis of this data, large discrepancies clearly exist among the three methods. In particular, between the theoretical (AP) and experimental (FR, KT) values, large deviations are observed. One reason for this deviation is caused by the experimental conditions. The determination of the $r$-parameters within the AP method is conducted in a semi-empirical manner. The $Q, e-$ values used are computed relative to styrene. In general, the type of the polymerization and additives, such as the initiators or chain transfer agent, are unknown. Good agreement with the experimental data is imposed for only MMA-co-CHMA (small triangle area). The values determined according to AP form a curve that runs from the second to the fourth quadrant. The experimental data, determined according to KT and FR, exhibit considerable scatter and are distributed from the first to the third quadrant. The individual experimental data for each copolymer matches quite well for the two linearization methods (FR, KT) in the most cases. Due to the small yields of approximately $10 \%$, both linearization methods can be applied. Basically, both methods are made for small conversations trending to zero. Since the KT method has been developed for higher conversions [30], the values appear to be somewhat more reliable; thus, the upcoming discussion will focus mainly on those $r$-parameters calculated with KT.

The various MMA- and EMA-based copolymers might be classified as follows: MMA-co-EMA and MMA-co-IBMA have an azeotropic point at $26.3 \mathrm{~mol} \%$ MMA or $66.6 \mathrm{~mol} \% \mathrm{MMA}$, respectively, as well as EMA-co- $n$-ButMA with 21.2 mol \% EMA. MMA-co-PrMA, MMA-co-CHMA, and EMA-co-IBMA are approximately truly random. The $r$-parameters are $r_{1}=0.761$ and $r_{2}=1.090$ for MMA-co-PrMA, $r_{1}=0.933$ and $r_{2}=1.201$ for MMA-co-CHMA, and $r_{1}=1.000$ and $r_{2}=0.811$ for EMA-co-IBMA. All three copolymerizations behave nearly truly randomly for a large number of compositions, as shown in the plotted copolymerization diagrams and the copolymer distribution according to Mayo-Lewis, respectively. The diagrams are shown in Figure 3. Other copolymers, for example, MMA-co-t-ButMA, MMA-co-BzMA, EMA-co-PrMA, EMA-co-t-ButMA, or EMA-co-BzMA, appear rather unsuitable for bulk copolymerizations. All of those copolymers are not (or at least only in some areas) close to the 
ideal distribution. Therefore, applications are limited to just a few compositions. If $r_{1}<1$ and $r_{2}>1$ or $r_{1}>1$ and $r_{2}<1$, then the copolymerization leads to a statistical copolymer in which monomer $2\left(r_{2}>1\right)$ or monomer $1\left(r_{1}>1\right)$, respectively, incorporates faster than the other monomer into the growing polymer chain. The aromatic comonomer BzMA shows the expected effect. Its activated double bond BzMA reacts faster into the growing polymer chain because of its associated monomer partner $\left(r_{2} \gg r_{1}\right)$.

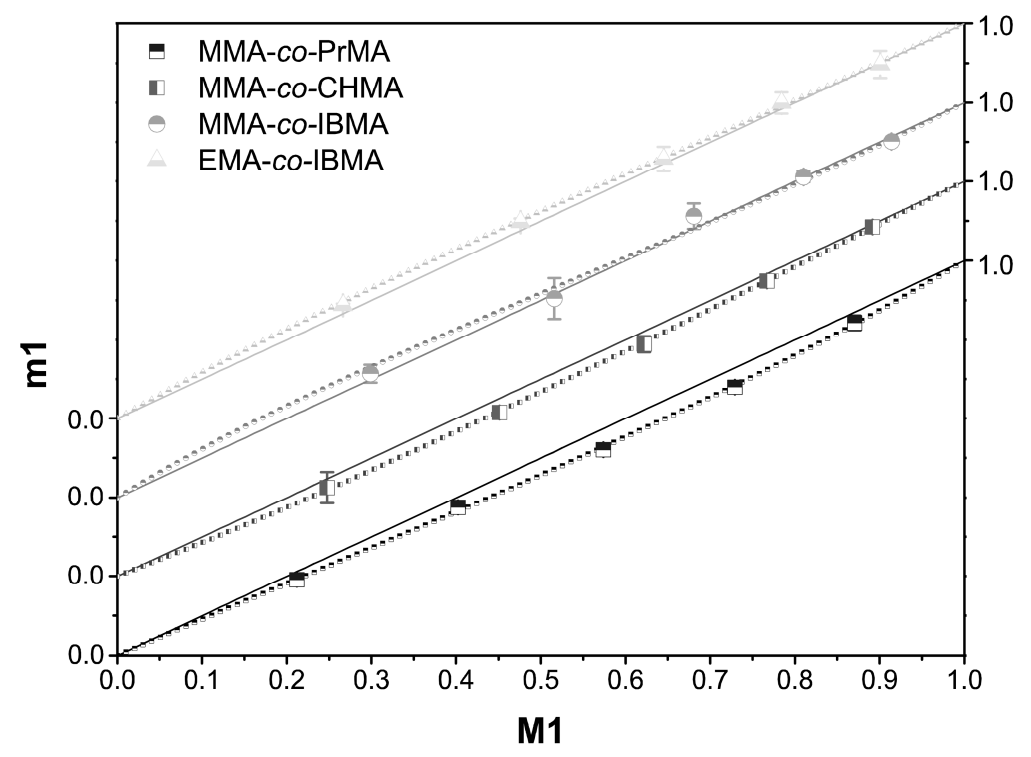

Figure 3. Axes adapted copolymerization diagram for the nearly truly random copolymers MMA-co-PrMA (half-filled squares top), MMA-co-CHMA (half-filled squares left), and EMA-co-IBMA (half-filled triangle bottom), and for the azeotropic copolymer MMA-co-IBMA (half-filled circle top, azeotropic point $66.6 \mathrm{~mol} \% \mathrm{MMA}$ ), each with the Mayo-Lewis plot (dots).

The copolymerization diagram in Figure 3 shows the individual compositions for the four most promising copolymers. For this purpose, the $y$-axis is shifted to give a better overview. The solid line denotes the bisector that reflects the ideal composition; the dotted line gives the distribution calculated by Mayo-Lewis. For the nearly truly random copolymers, the difference between the two lines is very small. The copolymer EMA-co-IBMA can serve as an example: for an EMA content of more than $60 \mathrm{~mol} \%$ and less than $30 \mathrm{~mol} \%$ the curves are almost identical, and they are still similar in the intermediate region. This copolymer might, therefore, be polymerized for many combinations in bulk. For the azeotropic copolymer MMA-co-IBMA, the azeotropic point can be observed as the interception point with the truly random copolymerization function (bisecting line). At the azeotropic point, the monomer mixture and the receiving polymer are equal.

\subsection{Thermo-Chemical Behavior}

The glass transition temperature $(\mathrm{Tg})$ is an important parameter to analyze the thermal behavior of thermoplastic copolymers and can be measured by differential scanning calorimetry (DSC). Investigation of the $\mathrm{Tg}$ was completed on precipitated polymer samples as well as on solid samples polymerized in bulk. The measurement results of the two fundamentally different experiments are quite comparable; nevertheless, the $\mathrm{Tg}$ of the precipitated polymers is found to be slightly higher. One reason for this observation is the better purification for the precipitated samples. By drying them under high vacuum, a smaller amount of residual monomer is present, as also confirmed by multiple repetitions of the DSC measurements from the solid samples. After the third rerun, the $T g$ for both experimental series are identical. An investigation of the $T g$ trend shows that copolymers with bulky side groups have increased values of $T g$ compared to polymers with linear 
alkylchains (see Table 1). This can be observed by comparing copolymers using IBMA and $n$-ButMA as comonomers. In addition, polymers with bulky side groups along the backbone have an increased stiffness. The sterically demanding isobornyl side group reduces the mobility of polymer chains and increases the $T g$. This effect can also be observed with copolymers containing $t$-ButMA as a comonomer. In contrast, comonomers (e.g., PrMA and $n$-ButMA) act as internal plasticizers and increase the chain mobility. Consequently, these copolymers have a decreased $T g$. In general, the value of $\mathrm{Tg}$ scales with the comonomer content. The value is adjustable in the range between 80 and $180{ }^{\circ} \mathrm{C}$, which is addressable to the glass transition temperature of the respective associated homopolymer. By increasing the comonomer content, the $\mathrm{Tg}$ can be tuned. In our case, the $\mathrm{Tg}$ of the base monomers is measured to be $80^{\circ} \mathrm{C}$ for poly-EMA and $120^{\circ} \mathrm{C}$ for poly-MMA. The highest $\mathrm{Tg}$ in the field is measured for poly-IBMA with $180^{\circ} \mathrm{C}$. However, poly-IBMA is very brittle and, thus, not usable as a homopolymer. The achievable $T g s$ of the remaining comonomers are $50^{\circ} \mathrm{C}$ for $n$-ButMA, $60^{\circ} \mathrm{C}$ for PrMA, $70{ }^{\circ} \mathrm{C}$ for BzMA, $115^{\circ} \mathrm{C}$ for CHMA, and $150{ }^{\circ} \mathrm{C}$ for $t$-ButMA. Of the other MMA-based copolymers, the substance MMA-co-CHMA is of particular interest because of its nearly constant $\mathrm{Tg}$. In all experiments, the $T g$ remained nearly unaffected, despite an increasing comonomer concentration in the copolymer. This property is especially useful for those types of applications that require slightly different material properties at constant processing conditions. An example of such a parameter is the refractive index, which can be adapted with a varying comonomer concentration [21]. Pre-structured preforms with different areas containing copolymers with varying comonomer content are possible with this technique. Indeed, in our current application case, we set a focus on the copolymers with an increased $\mathrm{Tg}$ for high temperature resistant polymer optical fibers (HT-POFs). Therefore, the copolymers MMA-co-IBMA and EMA-co-IBMA are selected for further investigations. Their linear scalable Tgs are shown in Figure 4. An increase in the $T g$ with increasing comonomer content is known for various copolymers. Examples are given in the literature by Koike et al. [33].

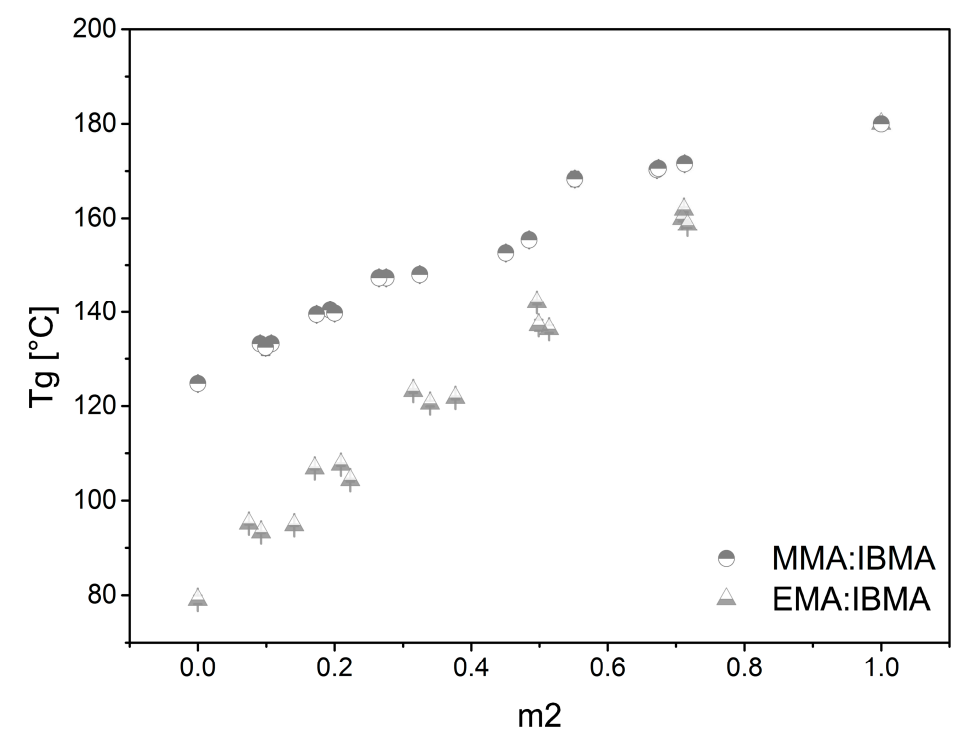

Figure 4. Glass transition temperatures for different comonomer contents $\left(\mathrm{m}_{2}\right)$. Copolymers MMA-co-IBMA (half-filled circle top) and EMA-co-IBMA (half-filled triangle bottom).

\subsection{Application Case HT-POF}

Two step index HT-POFs were prepared from two different HT materials with RMAT708 as the cladding material. The process was performed on the POF drawing tower as described in the experimental section. In detail, we used MMA-co-IBMA at the azeotropic point and EMA-co-IBMA at a 50:50 mixture; the expected $\mathrm{Tgs}$ for these copolymers are approximately 135 and $125^{\circ} \mathrm{C}$, respectively. The HT-POFs were manufactured in a preform process. Homogeneous preforms with a diameter of 
$8 \mathrm{~mm}$ could be prepared from both materials and drawn into POFs at the drawing tower. Up to $10 \mathrm{~m}$ POFs with a diameter of 710 to $980 \mu \mathrm{m}$ were obtained. The drawing temperature for these fibers is $230{ }^{\circ} \mathrm{C}$, the drawing speed was approximately one meter per minute. Similar conditions (preform diameter, speed, etc.) apply for a pure PMMA SI-POF as a reference. Thermal, mechanical and optical tests were conducted with the HT and the reference POF. The results are presented in Table 2.

Table 2. Fiber parameters.

\begin{tabular}{ccccc}
\hline Fiber & $\begin{array}{c}\text { Tensile Strength } \\
\left(\mathbf{N} / \mathbf{m m}^{2}\right)\end{array}$ & $\begin{array}{c}\text { Attenuation } \\
\mathbf{( d B / m})\end{array}$ & $\mathbf{T g}\left({ }^{\circ} \mathbf{C}\right)$ & $\begin{array}{c}\text { Decomposition } \\
\text { Onset }^{\text {a }}\left({ }^{\circ} \mathbf{C}\right)\end{array}$ \\
\hline PMMA (self-made) & 83 & $1-2$ & 124 & 93 \\
MMA:IBMA (33.4 mol \%) & 72 & $2-3$ & 135 & 251 \\
EMA:IBMA (50.0 mol \%) & 43 & $08-12$ & 125 & 234 \\
\hline \multicolumn{5}{c}{ a More than $1 \%$ mass loss. }
\end{tabular}

DSC and thermogravimetric analysis (TGA) were performed. The Tg was in the expected region from 125 to $135{ }^{\circ} \mathrm{C}$. A temperature of $135^{\circ} \mathrm{C}$ was found to be an acceptable threshold for HT-POF. The mass loss (TGA) was measured for fiber pieces. These were heated under air with a temperature ramp from 20 to $600{ }^{\circ} \mathrm{C}$. The decomposition onset for a weight loss of more than $1 \%$ goes up to $251{ }^{\circ} \mathrm{C}$ for the MMA-co-IBMA fiber $\left(234^{\circ} \mathrm{C}\right.$ for EMA-co-IBMA). Both fibers are strongly heat resistant, especially compared to PMMA-POF, for which the decomposition starts at $93^{\circ} \mathrm{C}$. For strain measurements, a setup with a pneumatic actuator and a force sensor was used. The tensile strength is in the area of 43-99 N/ $\mathrm{mm}^{2}$. Those values are approximately comparable to that of commercial PMMA fibers. [42] The lower mechanical strength for HT-POF is related to the stiffness of the polymers. Moreover, those values depend on the fiber drawing process and the strain measurement itself [43].

For optical analysis, the transmittance spectra were recorded on $18 \mathrm{~mm}$ test samples. In addition, the attenuation spectra were measured directly with the HT-POFs using the cut back method [33]. Both polymers are transparent in the visible region between $450-1000 \mathrm{~nm}$, as presented in Table 2 and Figure 5.

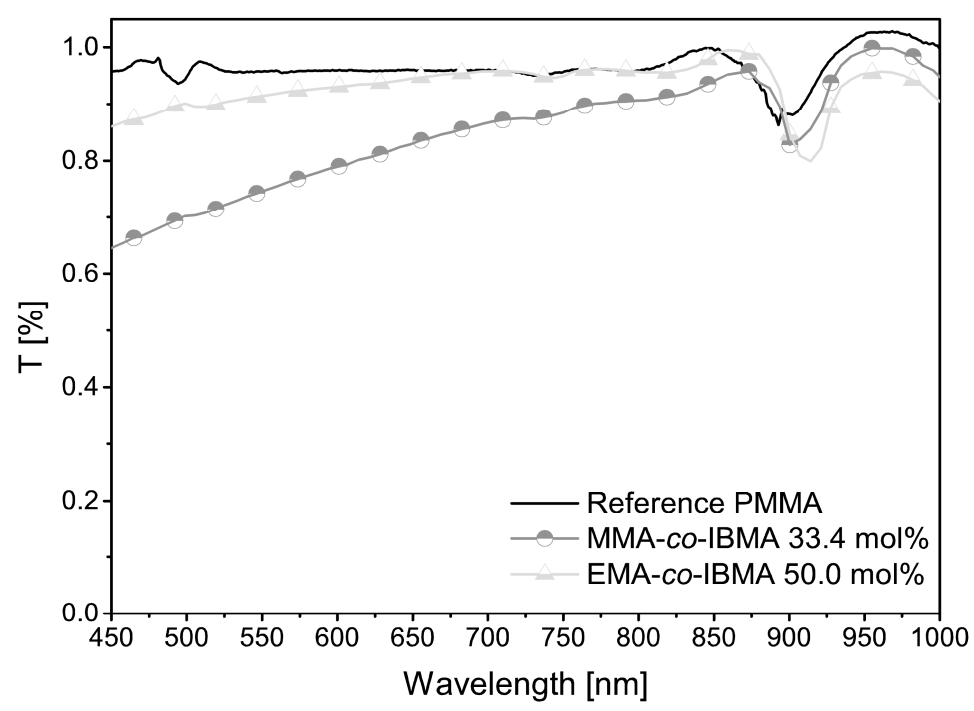

Figure 5. Transmittance spectra for $18 \mathrm{~mm}$ polymeric test samples in the spectral range from 450 to $1000 \mathrm{~nm}$. Samples: PMMA reference, MMA-co-IBMA with $33.4 \mathrm{~mol} \%$ comonomer content (azeotropic conditions) and EMA-co-IBMA with $50.0 \mathrm{~mol} \%$ comonomer content.

The two copolymeric materials do not reach the transparency of pure PMMA. EMA-co-IBMA $50.0 \mathrm{~mol} \%$ has a significantly higher transparency than MMA-co-IBMA with $33.4 \mathrm{~mol} \%$. At shorter 
wavelengths, the absorption increases even further. The decrease of transparency is homogeneous, so that a loss caused by scattering can be assumed. This scattering is likely caused by particles or impurities. Alternatively, this also could be explained by optical heterogeneities caused by a non-uniform copolymer composition [26]. The attenuation band of all polymers at approximately $900 \mathrm{~nm}$ can be explained by the typical $\mathrm{C}-\mathrm{H}$ harmonics which are red shifted with an increasing amount of IBMA. Therefore, the isobornyl substituent is causing a solvatochromic-like effect due to its non-polar chemical environment. The same applies to the slight increase at $730 \mathrm{~nm}$ [44]. As shown in Table 2, the attenuation spectra indicate very large values for all POFs. These values are very high compared with literature values for PMMA $(<0.2 \mathrm{~dB} / \mathrm{m}, 650 \mathrm{~nm}$ [42]) but are constant within the measurement series. The problem might be caused by the core cladding interface. A possible setting is a delamination of the layers because no extra adhesion layers were used. Moreover, the RMAT708 material, which is used for the cladding, is not specially designed for those (co)polymers. Microscopic pictures of our fibers' end face and side view are shown in Figure 6. On the dark edge between core and cladding the beginning of debonding can be seen. A copolymer HT-GI-POF based on styrene, with an acceptable spectral attenuation of $0.4 \mathrm{~dB} / \mathrm{m}(650 \mathrm{~nm})$, is already shown [22]. The present HT-SI-POFs, specifically the new acrylic copolymers MMA-co-IBMA with $33.4 \mathrm{~mol} \%$ comonomer content (azeotropic conditions) and EMA-co-IBMA with $50.0 \mathrm{~mol} \%$ comonomer content could have a positive development. Applications with this acrylate based copolymer systems might become possible within an optimized core-cladding structure. Most appealing is the end user friendly SI-POF architecture and the existing application structures, which is, for example, given in the MOST-BUS [45-47].

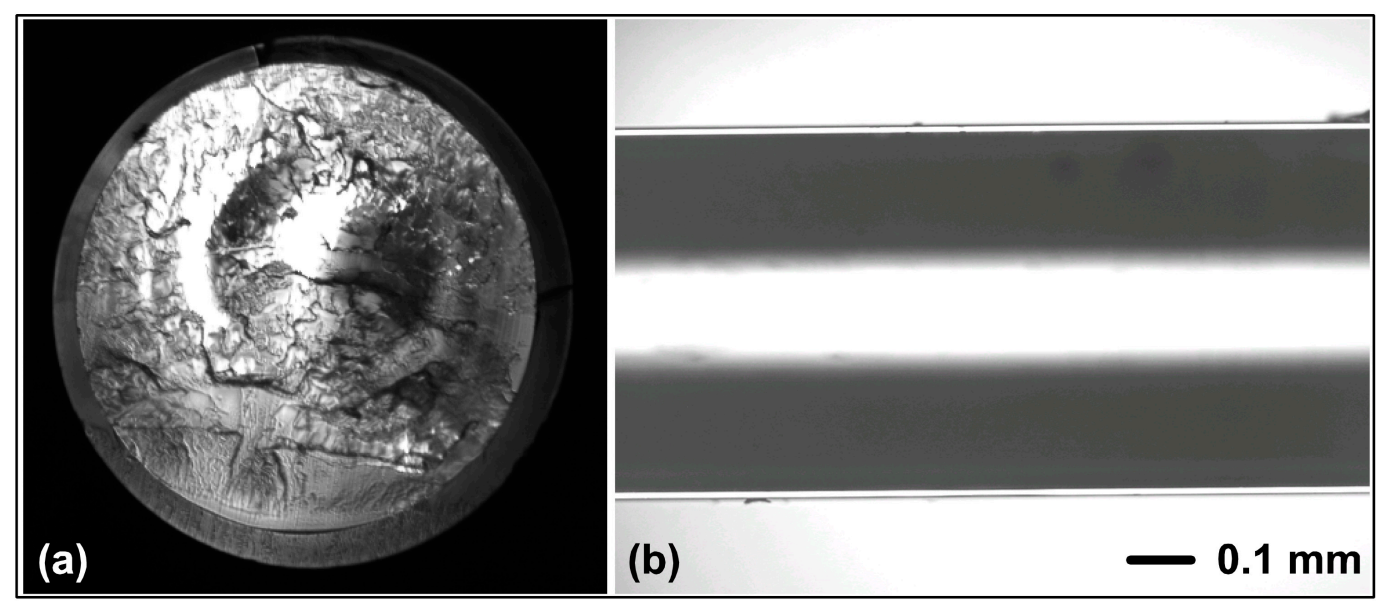

Figure 6. Copolymeric MMA-co-IBMA (33.4 mol \%) POF end face (a) and side view under a light microscope with $5 \times$ magnification $(\mathbf{b})$.

\section{Conclusions}

In the presented work, eight methacrylate type monomers were copolymerized, and fourteen different copolymers were obtained. These copolymers were either polymerized with a low conversion to determine their $r$-parameters or in bulk to obtain solid samples and fiber preforms. Due to their general transparency, they are of interest for use in optical applications. For our desired application case, i.e., POFs made from a preform process, the bulk polymerization becomes necessary, and only copolymers reacting truly randomly or azeotropically are useful. These are MMA-co-EMA, MMA-co-IBMA, EMA-co-MMA, and EMA-co- $n$-ButMA, which have an azeotropic point, and MMA-co-PrMA, MMA-co-CHMA, and EMA-co-IBMA, which are approximately truly random. In parts, the comparison between various evaluation methods (Fineman-Ross, Kelen-Tüdös, and Alfrey-Price) showed strong deviations. In general, the type of polymerization, solvents, and additives as the initiators are responsible for that result. HT-POFs with MMA-co-IBMA at the azeotropic point and EMA-co-IBMA at a 50:50 mixture were considered as an application case. Both polymers 
were found to have a high $T g$, a good thermal stability (according to TGA measurements), and usual mechanical strengths compared to PMMA. Functional model POFs were prepared to show the potential of the materials in a possible application. Those are needed for active POFs with high optical pump power, or for data transmission in regulated areas such as found in aircrafts, cars, and critical infrastructure.

Acknowledgments: We gratefully acknowledge the German Federal Ministry of Education and Research (BMBF) for funding the VIP-HOPE project (16V0010) and the German Federal Ministry for Economic Affairs and Energy (BMWi) for funding the LiLa-POF project (20E1510).

Author Contributions: Daniel Zaremba designed the Experiments, interpreted the experimental results and wrote the Paper; Robert Evert performed the fiber drawing and optical experiments; Laurie Neumann performed the EMA copolymerizations; Reinhard Caspary co-operated the fiberdrawing process; Wolfgang Kowalsky prepared the experimental background and supervision; Henning Menzel helped within the final editing and TGA measurements, Hans-Hermann Johannes co-operated chemical experiments and supervision.

Conflicts of Interest: The authors declare no conflict of interest.

\section{References}

1. The Zettabyte Era: Trends and Analysis. Available online: http://www.cisco.com/c/en/us/solutions/ service-provider/visual-networking-index-vni/white-paper-listing.html (accessed on 28 November 2016).

2. Koutitas, G.; Demestichas, P. A review of energy efficiency in telecommunication networks. Telfor J. 2010, 2, 2-7.

3. Ciordia, O.; Esteban, C.; Pardo, C.; Pérez de Aranda, R. Commercial silicon for gigabit communication over SI-POF. In Proceedings of the 22nd International Conference on Plastic Optical Fibers, POF 2013, Búzios, Brazil, 11-13 September 2013; Volume 22, pp. 109-116.

4. Reviriego, P.; Perez-Aranda, R.; Pardo, C. Introducing energy efficiency in the VDE 0885-763 standard for high speed communication over plastic optical fibers. IEEE Commun. Mag. 2013, 51, 97-102. [CrossRef]

5. Agrawal, G.P. Fiber-Optic Communication Systems, 3rd ed.; John Wiley \& Sons: New York, NY, USA, 2002; pp. 23-28.

6. Koike, Y.; Ishigure, T.; Nihei, E. High-bandwidth graded-index polymer optical fiber. J. Lightw. Technol. 1995, 13, 1475-1489. [CrossRef]

7. Koike, Y.; Asai, M. The future of plastic optical fiber. NPG Asia Mater. 2009, 1, 22-28. [CrossRef]

8. Giaretta, G.; White, W.; Wegmuller, M.; Onishi, T. High-speed (11 Gbit/s) data transmission using perfluorinated graded-index polymer optical fibers for short interconnects $(<100 \mathrm{~m})$. IEEE Photonics Technol. Lett. 2000, 12, 347-349.

9. White, W. Graded-index POF in active optical cables. In Proceedings of the 24th International Conference on Plastic Optical Fibers, POF 2015, Nuremberg, Germany, 11-13 September 2015; Volume 24, p. 312.

10. Van den Boom, H.P.A.; Li, W.; van Bennekom, P.K.; Tafur Monroy, I.; Giok-Djan, K. High-capacity transmission over polymer optical fiber. IEEE J. Sel. Top. Quantum Electron. 2001, 7, 461-470. [CrossRef]

11. Schlepple, N.; Nishigaki, M.; Uemura, H.; Furuyama, H.; Sugizaki, Y.; Shibata, H.; Koike, Y. Ultracompact $4 \times 3.4$ Gbps optoelectronic package for an active optical HDMI cable. IEEE CPMT Symp. Jpn. 2012, 1-4. [CrossRef]

12. Takizuka, H.; Torikai, T.; Mitsui, A.; Suzuki, H.; Watanabe, Y.; Toma, T.; Koike, Y. A proposal of novel optical interface to transmit 8K-UHDTV for consumer applications. In Proceedings of the 18th Microoptics Conference, MOC'13, Tokyo, Japan, 27-30 October 2013; p. 14043816.

13. Toma, T.; Takizuka, H.; Torikai, T.; Suzuki, H.; Ogi, T.; Koike, Y. Development of a household high-definition video transmission system based on ballpoint-pen technology. Synthesiology 2014, 7, 118-128. [CrossRef]

14. Beckers, M.; Schlüter, T.; Vad, T.; Gries, T.; Bunge, C.-A. An overview on fabrication methods for polymer optical fibers. Polym. Int. 2015, 64, 25-36. [CrossRef]

15. Zubia, J.; Arrue, J. Plastic optical fibers: An introduction to their technological processes and applications. Opt. Fiber Technol. 2001, 7, 101-140. [CrossRef]

16. Kuzyk, M.G. Polymer Fiber Optics: Materials, Physics, and Applications; CRC: Boca Raton, FL, USA, 2007; pp. 53-68. 
17. Daum, W. Reliability of polymer optical fibres. In Proceedings of the 27th European Conference on Optical Communication, ECOC'01, Amsterdam, The Netherlands, 30 September-4 October 2001; pp. 68-69.

18. Flipsen, T.A.C.; Steendam, R.; Pennings, A.J.; Hadziioannou, G. A novel thermoset polymer optical fiber. Adv. Mater. 1996, 8, 45-48. [CrossRef]

19. Peters, K. Polymer optical fiber sensors-A review. Smart Mater. Struct. 2011, 20, 17. [CrossRef]

20. Bilro, L.; Alberto, N.; Pinto, J.L.; Nogueira, R. Optical sensors based on plastic fibers. Sensors 2012, 12, 12184-12207. [CrossRef] [PubMed]

21. Peng, G.D.; Chu, P.L.; Xiong, Z.; Whitbread, T.W.; Chaplin, R.P. Dye-doped step-index polymer optical fiber for broadband optical amplification. J. Lightw. Technol. 1996, 14, 2215-2223. [CrossRef]

22. Kondo, A.; Araki, T.; Koike, Y. Binary amorphous copolymers based graded index polymer optical fiber. In Proceedings of the 21st International Conference on Plastic Optical Fibers, POF 2012, Atlanta, GA, USA, 10-12 September 2012; Volume 21, pp. 74-77.

23. Koike, K.; Mikeš, F.; Okamoto, Y.; Koike, Y. Design, synthesis, and characterization of a partially chlorinated acrylic copolymer for low-loss and thermally stable graded index plastic optical fibers. J. Polym. Sci. A 2009, 47, 3352-3361. [CrossRef]

24. Zaremba, D.; Evert, R.; Cichosch, A.; Caspary, R.; Kowalsky, W.; Johannes, H.-H. Novel concepts for copolymer based high temperature POFs. In Proceedings of the 23rd International Conference on Plastic Optical Fibers, POF 2014, Yokohama, Japan, 8-10 October 2014; Volume 23, pp. 69-73.

25. Möhl, S.; Cichosch, A.; Schütz, S.; Caspary, R.; Kowalsky, W.; Johannes, H.-H. Materials for polymer optical fiber amplifiers. In Proceedings of the 21st International Conference on Plastic Optical Fibers, POF 2012, Atlanta, GA, USA, 10-12 September 2012; Volume 21, pp. 50-55.

26. Koike, Y.; Tanio, N.; Ohtsuka, Y. Light scattering and heterogeneities in low-loss poly(methy-methacrylate) glasses. Macromolecules 1989, 22, 1367-1373. [CrossRef]

27. Zaremba, D.; Evert, R. Materials, chemical properties and analysis. In Polymer Optical Fibres; Woodhead Publishing: Duxford, UK, 2017; pp. 153-186.

28. Tieke, B. Makromolekulare Chemie, 2nd ed.; Wiley-VCH: Weinheim, Germany, 2012; pp. 146-163.

29. Fineman, M.; Ross, S.D. Linear method for determining monomer reactivity ratios in copolymerization. J. Polym. Sci. 1950, 5, 259-262. [CrossRef]

30. Kelen, T.; Tüdös, F. Analysis of the linear methods for determining copolymerization reactivity ratios. I. A new improved linear graphic method. J. Macromol. Sci. Part A 1975, 1, 1-27. [CrossRef]

31. Alfrey, T.; Price, C.C. Relative reactivities in vinyl copolymerization. J. Polym. Sci. 1947, 2, 101-106. [CrossRef]

32. Schütz, S. Optische Spezialfasern aus Polymeren und Fluoridglas; Dr. Hut: München, Germany, 2013; pp. 35-44.

33. Koike, Y. Fundamentals of Plastic Optical Fibers; Wiley-VCH: Weinheim, Germany, 2015; pp. 84-86.

34. Polymer Handbook; Brandrup, J., Immergut, E.H., Grulke, E.A., Abe, A., Bloch, D.R., Eds.; Wiley: New York, NY, USA, 1989.

35. Greenley, R.Z. An expanded listing of revised $Q$ and $e$ values. J. Macromol. Sci. Part A 1980, 14, 427-443. [CrossRef]

36. Fasla, A.; Ould Kada, S.; Seghier, Z.; Périchaud, A. Cyclohexyl methacrylate with tetra (ethylene glycol) dimethacrylate in tertahydrofuran radical copolymerization. Mater. Sci. Forum 2009, 609, 63-67. [CrossRef]

37. Imoto, M.; Otsu, T.; Tsuda, K.; Ito, T. Vinyl Polymerization. LXXIII. Polymerization and copolymerization of bornyl or isobornyl methacrylate. J. Polym. Sci. A 1964, 2, 1407-1419. [CrossRef]

38. Kobayashi, T.; Nakatsuka, S.; Iwafuji, T.; Kuriki, K.; Imai, N.; Nakamoto, T.; Claude, C.D.; Sasaki, K.; Koike, Y.; Okamoto, Y. Fabrication and superfluorescence of rare-earth chelate-doped graded index polymer optical fibers. Appl. Phys. Lett. 1997, 71, 2421. [CrossRef]

39. Yu, J.; Tao, X.; Tam, H. Fabrication of UV sensitive single-mode polymeric optical fiber. Opt. Mater. 2006, 28, 181-188. [CrossRef]

40. Cichosch, A. Entwicklung von Materialien für den Einsatz in Polymer Optischen Faserverstärkern; Dr. Hut: München, Germany, 2015; pp. 85-86.

41. Mayo, F.R.; Lewis, F.M. Copolymerization, I. A basis for comparing the behavior of monomers in copolymerization; the copolymerization of styrene and methyl methacrylate. J. Am. Chem. Soc. 1944, 66, 1594-1601. [CrossRef]

42. Ziemann, O.; Krauser, J.; Zamzow, P.E.; Daum, W. POF-Handbuch: Optische Kurzstrecken-Übertragungssysteme (German Edition); Springer: Dordrecht, The Netherlands, 2007; pp. 79-90. 
43. Yang, D.; Yu, J.; Tao, X.; Tam, H. Structural and mechanical properties of polymeric optical fiber. Mater. Sci. Eng. A 2004, 364, 256-259. [CrossRef]

44. Graf, J. Entwicklung und Untersuchungen zur Herstellung Verlustarmer Passiver Wellenleiter und Verstärkender Wellenleiter; Universitätsbibliothek Universität des Saarlandes: Saarbrücken, Germany, 1999; pp. 27-32.

45. Strobel, O.; Rejeb, R.; Lubkoll, J. Communication in automotive systems: Principles, limits and new trends for vehicles, airplanes and vessels. In Proceedings of the 12th International Conference on Transparent Optical Networks, ICTON 2010, Munich, Germany, 27 June-1 July 2010; pp. 1-6.

46. Seibl, D.; Bohm, M.; Strobel, O. Polymer-optical-fiber data bus technologies for MOST applications in vehicles. In Proceedings of the 2nd ICTON Mediterranean Winter, Marrakech, Morocco, 11-13 December 2008; Volume 2, pp. 1-6.

47. Zeeb, E. Optical communication, optical data bus systems in cars: current status and future challenges. In Proceedings of the 27th European Conference on Optical Communication, ECOC'01, Amsterdam, The Netherlands, 30 September-4 October 2001; pp. 70-71.

(C) 2017 by the authors; licensee MDPI, Basel, Switzerland. This article is an open access article distributed under the terms and conditions of the Creative Commons Attribution (CC BY) license (http:/ / creativecommons.org/licenses/by/4.0/). 